\title{
Factors Affecting Health Behaviors in Late School-aged Children from Multicultural Families
}

\author{
Sangmi Lee \\ Associate Professor, Department of Nursing, Dongyang University, Yeongju, Korea
}

\begin{abstract}
Purpose: This study was conducted to investigate factors affecting health behaviors in late school-aged children from multicultural families. Methods: This study included 401 children (112 from multicultural families and 289 from non-multicultural backgrounds) in grades $4 \sim 6$ in 11 elementary schools. Data on health behaviors and related factors (school adjustment, the mother-child relationship, self-efficacy, etc.) were collected from the children using self-reported questionnaires between May and June in 2019. The collected data were analyzed through a univariate analysis and multiple regression analysis. Results: The health behavior score of multicultural children was lower than that of non-multicultural children $(t=3.32, p=.001)$. In multicultural children, school adjustment $(\beta=.55, p<.001)$, mother-child relationship $(\beta=.25, p=.001)$, and perceived health status (very healthy=1; $\beta=.19, p=.011)$ were significant factors affecting their health behavior and explained $47.0 \%(\mathrm{~F}=30.93, p<.001)$ of the variance. Conclusion: Multicultural late school-aged children are at risk to engage in a lower level of health behaviors than their non-multicultural counterparts. More attention should be paid to ways of improving multicultural children's perceptions of their health status, maternal relationships, and school adjustment in order to promote health behaviors.
\end{abstract}

Key words: Health behavior; Child; Mother-child relations; Cultural diversity; Family

\author{
Corresponding author Sangmi Lee \\ https://orcid.org/0000-0002-7611-670X \\ Department of Nursing, Dongyang University, \\ 145 Dongyangdae-ro, Punggi-eup, Yeongju 36040, Korea \\ TEL +82-54-630-1712 FAX +82-54-630-1371 \\ E-MAIL Ism95@dyu.ac.kr \\ *This study was supported by the research fund of Dongyang University in \\ 2018.
}

Received Aug 28, 2019 Revised Sep 26, 2019 Accepted Sep 28, 2019

(a) This is an Open Access article distributed under the terms of the Creative Commons Attribution NonCommercial License (http://creativecommons.org/licenses/by-nc/4.0/) which permits unrestricted noncommercial use, distribution, and reproduction in any medium, provided the original work is properly cited.

\section{INTRODUCTION}

\section{Need for Study}

The proportion of elementary, middle, and high school students in Korea from multicultural families is steadily rising, with an increase from $0.7 \%$ in 2012 to $2.2 \%$ in 2018; furthermore, the majority of multicultural students $(76.2 \%)$ are in elementary school [1]. In the Korean context, multicultural students refer to children who are from families where one or both parents are foreigners. It has become common in Korea for children to be born in the setting of an international marriage between a foreign woman who emigrated for marriage and a Korean man, due to numerous complex social phenomena, such as recent economic developments, women's high educational attainment, the reduced marriage rate of women linked to their social advancement, the higher proportion of men than women among older unmarried people (over 40 years of age), and the low birthrate [1].

Multicultural couples are prone to conflict due to linguistic and cultural differences, and since the male partners in these relationships are often older or of low socioeconomic status, there is also a high risk of conflict due to the generation gap and financial problems; taken together, both these conflicts 
and their underlying causes may influence their children [2]. Furthermore, mothers in multicultural families tend to have an insufficient understanding of child rearing and health care, due to the expectation that they give birth to a child within a short period after immigration, a problem exacerbated by the tendency of the father or grandparents to raise children according to traditional methods, which involve providing improper health care to children and place them at a higher risk of health problems [3]. In particular, most foreign mothers in Korea are women who emigrate from underdeveloped regions of Southeast Asia, such as Vietnam [1]. These mothers may lack adequate education on concepts of personal and public hygiene, increasing their risk of providing improper health care, which may in turn also have effects on their children's health behaviors.

Health behaviors are essential factors for maintaining and promoting health and preventing disease, and given that health habits formed at an early age tend to affect one's health throughout the lifetime [4], desirable health behaviors during childhood lay the foundation for ensuring optimal growth and development and becoming a healthy adult. School age is a period when through increased independence from their environment and an improved ability to control their behavior [5], children begin to independently perform health behaviors that previously depended on parents or caregivers, a transition that widens the gap between children in terms of health behaviors. For this reason, research into the health behaviors of school-age children in Korea has become more active in recent years [6-10], with most studies targeting late school-aged children (specifically in the fourth to sixth grades in elementary school) who are able to give self-reports on their own behaviors [6-9]. Some research has investigated children from the vulnerable environment of low-income households, who are at a higher risk of poor health performance, but few studies in Korea have conducted health behavior surveys among multicultural children [11].

Individuals' health behavior is affected by their internal and environmental characteristics [12]. Low socioeconomic status reduces perceptions and practices of health behaviors, and health problems and degree of obesity are well-known internal factors that negatively interact with health behaviors such as physical activity, eating habits, and lifestyle [12]. In addition, since self-efficacy is a direct predictor of one's behaviors and will, high self-efficacy has the effect of stimulating behavioral change by strengthening self-control of one's behaviors, thereby ultimately promoting health behaviors [13]. Thus, self-efficacy should be included in analyses of the health behaviors of socially vulnerable children, who are more likely to experience low self-efficacy.

Parents, as the shapers of children's most intimate environ- ment, act as role models for health behaviors, as well as educators and facilitators [14]. In other words, emotional support and adequate supervision from parents improve children's quality of life, and also control inappropriate health behaviors and promote proper behaviors. However, foreign mothers and multicultural families may lack a full understanding of their children, exposing them to a greater risk of low-quality parent-child relations. Especially when their children become elementary school students and begin to follow the regular school curriculum, foreign mothers face difficulties in guiding their children to learn due to their different sociocultural background, the unfamiliarity of the curriculum, and their poor Korean proficiency. The low parenting efficacy that stems from mothers' poor ability to guide their children's learning further disturbs their relationship with their children, and it therefore may be easier for children to disregard their mothers or demonstrate negative attitudes toward them [15]. This interrupts the formation of the mother-child relationship and interfere with mothers' roles as the health behavior educators and facilitators for their children.

Moreover, school is the environment where late schoolaged children spend most of their time (in addition to home) and are exposed to various influences, and their health behaviors are correlated with their adaption to-and satisfaction with-school life [7]. School adjustment is an inclusive concept that refers to the overall school life of children, including their attitudes toward academic performance, compliance with school regulations, relationships with peers or teachers, and satisfaction with school life [16]. Considering the magnitude of school's influence on school-aged children [4], school adjustment can be a significant factor affecting children's quality of life and even lifestyle factors, such as health behaviors. However, multicultural children may have difficulties making friends of their own age due to their exotic appearance, language problems, or underachievement in school, and they are therefore susceptible to difficulties in school adjustment, including experiences of psychological problems, refusal to attend school due to bullying [15], and timidity stemming from a sense of repulsion, humiliation, and isolation due to their unusual family environment, which is different from that of their peers [17]. In a large-scale longitudinal study of 3,808 first-grade elementary students in Korea [18], peer relationships showed significant correlations with scores on the Child Behavior Checklist, which is used to evaluate children's social adjustment, emotion, and behavioral problems, as well as with emotional and behavioral problems measured using the Youth Self Report in early adolescence (13 15 years of age). These findings demonstrate the short- and long-term influence of peer relationships of school-aged children on their ability to achieve optimal social outcomes. Therefore, it is 
necessary to elucidate the relationships between health behaviors and the internal and environmental characteristics of multicultural children, which are likely to negatively influence their health-related behaviors. Since recent health behavior-related research on children from multicultural families in Korea has only been carried out in adolescents to a limited extent using Youth Health Behavior Online Survey data [11], it is necessary to compare the health behavior status of multicultural school-aged children and that of children from non-multicultural families with the goal of identifying factors related to health behaviors as a basis for developing strategies for health behavior promotion in multicultural school-aged children.

\section{Purpose}

This study aimed to investigate factors affecting health behaviors in late school-aged children from multicultural families and to explore factors affecting these behaviors. Its specific goals were to compare health behaviors, the mother-child relationship, school adjustment, and self-efficacy between late school-aged multicultural children and their non-multicultural peers; to identify correlations between health behaviors and children's general characteristics, the mother-child relationship, school adjustment, and efficacy; and finally, to analyze the factors affecting health behaviors of multicultural children.

\section{METHODS}

\section{Study Design}

This is a descriptive research study aiming to investigate health behaviors in late school-aged children from multicultural families in comparison with children from non-multicultural families and to analyze the factors affecting the health behaviors of multicultural children.

\section{Subjects}

The subjects of this study were late school-aged children from multicultural and non-multicultural families, including all of the fourth- to sixth-grade students from a convenience sample of 11 elementary schools in town and village units of North Gyeongsang Province in which multicultural families form a large percentage of the population. The subjects were children who had enough Korean-language proficiency to fill out the questionnaire on their own and provided written consent to participate in the study. A total of 414 children participated, including multicultural children with foreign mothers and children from non-multicultural families where both parents were Korean. The final analysis included 401 children (112 multicultural children and 289 non-multicultural children) after excluding 13 children with missing data for basic information such as maternal nationality. The sample size exceeded the necessary sample size of 85 multicultural children determined using the $\mathrm{G}^{*}$ Power 3.1 program with an intermediate effect size of .14, a significance factor of .05, a power of .80 , and with four independent variables to be considered in the multiple regression analysis.

\section{Data Collection}

Before data collection, we received approval to conduct the research from the Institutional Review Board of the institution to which the researcher of this study was affiliated (approval number 1041495-201903-HR-03-01). The researcher then visited the participating elementary schools and explained the purpose and methods of the study to the head of the institution (principal or vice-principal), after which data were collected from May to June of 2019 from the institutions that agreed for students to participate. In accordance with the circumstances of the specific institutions, either the researcher or a class teacher who fully understood the purpose and methods of the study visited fourth- to sixth-grade classrooms to inform them of the purpose and methods of the study and their choice between voluntary participation or refusal, and then collected data from the subjects who provided written consent to participate. In this study, all information except for physical measurement values (weight, height) were gathered by a 4-page questionnaire survey on A4 paper, which took 20 minutes to fill out. For the weight and height of the subjects, measurement values to the first decimal place were collected at a medical clinic (for fourth-graders) or stadiometers in the school (for fifth- and sixth-graders) as part of student health check-ups that took place from April to May 2019. The subjects were also each provided with a small reward.

\section{Study Tools}

The dependent variable of this study was health behavior, and the predictors of the dependent variable were general characteristics (gender, grade, adiposity, perceived health status, perceived economic status, etc.), their mother-child relationship, school adjustment, and self-efficacy.

\section{1) Health behaviors}

To investigate the health behaviors of elementary school students, we used (with approval) the tool that was developed by Kim, Yang, Jeong, and Lee [19] and then modified and sup- 
plemented on the basis of health guidelines by Park [9]. This tool consists of a total of 53 questions in 6 subcategories, including 10 questions on individual hygiene, 9 on eating habits, 6 on exercise, 10 on mental health, 10 on disease prevention, and 8 on accident prevention. The items were scored on a 4-point Likert scale, with 'never' as 1 point and 'always' as 4 points, implying that the higher the total score, the higher the level of health promotion behaviors. The reliability of the tool-represented by Cronbach's $\alpha$-was .94 for the entire tool and .75 .83 for the sub-dimensions in Park's study [9], and .93 for the entire tool and .68 .81 for the sub-dimensions in our study.

\section{2) Body mass index and adiposity}

Body mass index (BMI) is calculated by dividing weight $(\mathrm{kg})$ by height squared $\left(\mathrm{m}^{2}\right)$, and adiposity was defined according to the classification criteria of the 2017 Pediatric Growth Chart [20]. Underweight was defined as an age-specific weight under the 5 th percentile, overweight as an agespecific BMI greater than the 85th percentile and less than the 95th percentile, and obesity as an age-specific BMI greater than or equal to the 95th percentile.

\section{3) Perceived health status}

Perceived health status was evaluated by a single question regarding the subject's own opinion of his or her current health status, as has been done in previous studies to determine participants' subjective health status [6,11]. The question was answered using a Likert scale, with 'very unhealthy' as 1 point and 'very healthy' as 4 points, meaning that the higher the total score, the better the perceived health status.

\section{4) Mother-child relationship}

In order to evaluate the mother-child relationship among late school-aged children, the tool developed by Lee and Kim [21] was used. This tool uses the same questions to evaluate a child's perceived relationship with his or her mother or father, although it was utilized in this study to investigate specifically mother-child relationships. The tool consists of 30 questions distributed among 5 subcategories, with 10 questions on intimacy/support, 7 on authority/control, 5 on the parental relationship, 4 on great expectations, and 4 on permissiveness. The responses were on a 5-point Likert scale, with 'absolutely not true' as 1 point and 'very true' as 5 points, meaning that the higher the total score, the higher the quality of the parent-child relationship. Cronbach's $\alpha$, as an indicator of the reliability of the tool, was .89 for the entire tool and .73 .87 for the sub-dimensions in Lee and Kim's study [21], while the corresponding values were .89 for the entire tool and .79 .92 for the sub-dimensions in this study.

\section{5) School adjustment}

The tool developed by Joe and Doh [16] was used with the author's approval to evaluate school adjustment in the late school-aged children. This tool consists of 30 questions in 4 subcategories, with 9 questions on academic attitudes and rule observance, 7 on relationships with peers, 8 on relationships with teachers, and 6 on school satisfaction. The items were answered on a 4-point Likert scale, with 'almost never' as 1 point and 'very true' as 4 points, implying that the higher the total score, the greater the school adjustment. Cronbach's $\alpha$, as an indicator of the reliability of the tool, was .91 .93 for the sub-dimensions in Joe and Doh's study [16], while its values were .96 for the entire tool and .86 .92 for its sub-dimensions in this study.

\section{6) Self-efficacy}

The Korean Adaptation of the General Self Efficacy Scale [22], which was developed by Schwarzer and Jerusalem [23], was utilized to evaluate self-efficacy. This tool is allowed to be used through the original developer's official website (http:// userpage.fu-berlin.de/ health/korean.htm) without special approval. This tool, consisting of 10 questions, was scored using a 4-point Likert scale with 'absolutely not true' as 1 point and 'very true' as 4 points, meaning that the greater the total score, the higher the self-efficacy. Cronbach's $\alpha$, reflecting the reliability of this tool, was .75 in Schwarzer and Jerusalem's study [23] and .92 in our study.

\section{Data Analysis}

The data collected from this study were analyzed by SPSS Statistics 23 for Windows (IBM Corp., Armonk, NY, USA), the skewness and kurtosis of the major variables (health behaviors, perceived health status, mother-child relationship, school adjustment, self-efficacy) for multicultural children were in the range of -2 to +2 , which enabled us to assume a normal distribution and to analyze the data using parametric tests. The general characteristics, health behaviors, perceived health status, mother-child relationship, school adjustment, and self-efficacy of multicultural and non-multicultural children were analyzed using descriptive statistics (average, standard deviation, frequency, and percentage), while the independent t-test and $x^{2}$ test were used to compare major variables between the two groups. Health behaviors were analyzed according to the general characteristics of multicultural children using the independent t-test and one-way analysis of variance, and Pearson correlation coefficients were used to determine the correlations of health behaviors with major variables. The factors affecting subjects' health behaviors were analyzed using multiple regression analysis. 


\section{RESULTS}

\section{Comparison of General Characteristics and Major Vari- ables between Multicultural and Non-multicultural Children}

Multicultural children made up $27.9 \%$ of the 401 total subjects, and the majority of the mothers of the multicultural children were Vietnamese (78.6\%), followed by $8.0 \%$ Filipinas, and $7.1 \%$ Chinese. Among the participants' general characteristics, grade, perceived economic status, and cohabiting family members showed statistically significant differences between multicultural and non-multicultural children. The multicultural children were predominantly fourth-graders, while the non-multicultural children were mostly sixth-graders $\left(x^{2}=9.21, p=.010\right)$, and the multicultural children had a higher proportion of self-perceived 'average' or 'difficult' economic status than the non-multicultural children $\left(x^{2}=17.77, p<.001\right)$. Additionally, a higher proportion of multicultural children lived together with their father $\left(x^{2}=6.58, p=.009\right)$ and grandparents $\left(x^{2}=49.49, p<.001\right)$, but a lower percentage lived with their mothers $\left(x^{2}=23.10, p<.001\right)$ and older siblings $\left(x^{2}=22.79\right.$, $p<.001$ ) (Table 1 ).

The overall average score for health behaviors $(\mathrm{t}=3.32, p=$ $.001)$, the mother-child relationship $(\mathrm{t}=6.75, p<.001)$, school adjustment $(\mathrm{t}=2.30, p=.022)$, and self-efficacy $(\mathrm{t}=2.05, p=.041)$ were all significantly lower in multicultural children than in non-multicultural children (Table 1). Differences in health behavior scores between the two groups were analyzed according to grade, perceived economic status, and cohabitation with the mother, which are general characteristics that showed significant differences between multicultural and non-multicultural children. The analysis showed that the health behavior scores analyzed according to each of those three variables were consistently lower for multicultural children than for their non-multicultural counterparts. In particular, among sixth-graders $(t=2.07, p=.040)$, those with a 'prosperous' economic status $(\mathrm{t}=2.26, p=.026)$, and those who cohabited with their mothers $(\mathrm{t}=2.37, p=.018)$, multicultural children showed statistically significantly lower health behavior scores than non-multicultural children (Table 2).

\section{Differences in Health Behaviors among Multicultural Children in Relation to Their General Characteristics}

The overall average score for multicultural children's health behaviors showed a significant difference ( $\mathrm{F}=8.81, p<.001)$ in relation to their perceived health status, and was statistically significantly higher in the 'very healthy' group than in the 'healthy' and 'unhealthy' groups, as confirmed by a post-hoc test (Scheffé test). Disease prevention-one of the health behavior subcategories-showed a significant difference in relation to adiposity ( $\mathrm{F}=6.54, p=.002)$, and the Scheffé test confirmed that the average score was significantly lower in underweight respondents than in normal, overweight, or obese respondents, while mental health was significantly higher among participants who had older siblings than among those who $\operatorname{did} \operatorname{not}(\mathrm{t}=2.31, p=.023)$ (Table 3$)$.

\section{Correlations between Health Behaviors, School Adjust- ment, Parent-Child Relationship, and Self-efficacy in Multi- cultural Children}

The overall score for health behaviors showed a statistically significant positive correlation with the mother-child relation$\operatorname{ship}(\mathrm{r}=.37, p<.001)$, school adjustment $(\mathrm{r}=.62, p<.001)$, and self-efficacy ( $\mathrm{r}=.44, p<.001)$, but no statistically significant relationship with body mass index (Table 4).

\section{Factors Affecting the Health Behaviors of Multicultural Children}

In order to identify factors affecting multicultural children's health behaviors, we carried out multiple regression analysis using the overall score for health behaviors as the dependent variable. Perceived health status, the mother-child relationship, school adjustment, and self-efficacy, which showed statistically significant $(p<.050)$ correlations with the overall score for health behaviors in the univariate analysis, were chosen as independent variables and entered into the regression model in a stepwise method. Perceived health status, which is a categorical variable, was converted into a dummy variable with responses of 'less than healthy' set as 0 and 'very healthy' as 1 . The analysis included 102 subjects who had no missing values for the included variables, and the Durbin-Watson index of the model was 1.77, meaning that there was no autocorrelation among the independent variables. The tolerance limit was over .1 (.8 .9) and the variance inflation factor was lower than 10 (1.0 1.1), proving that there was no multicollinearity. The variables that exerted a significant influence on health behaviors were-in descending order-school adjustment $(\beta=.55, p<.001)$, the mother-child relationship ( $\beta=$ $.25, p=.001$ ), and perceived health status ('very healthy' $=1 ; \beta=$ $.19, p=.011)$. The model was statistically significant $(\mathrm{F}=30.93$, $p<.001$ ), with an explanatory power of $47.0 \%$ (Table 5 ).

\section{DISCUSSION}

The late-school period is a time when the gap in health behaviors among children can widen, as the independence of 
Table 1. Differences in General Characteristics and Main Variables between Multicultural and Non-multicultural Children

$(N=401)$

\begin{tabular}{|c|c|c|c|c|c|c|}
\hline \multirow[t]{2}{*}{ Variables } & \multirow[t]{2}{*}{ Categories } & Total & \multirow[t]{2}{*}{ Range } & \multirow{2}{*}{$\begin{array}{c}\text { Multicultural } \\
\text { children }(\mathrm{n}=112)\end{array}$} & \multirow{2}{*}{$\begin{array}{c}\begin{array}{c}\text { Non-multicultural } \\
\text { children }(\mathrm{n}=289)\end{array} \\
\mathrm{n}(\%) \text { or } \mathrm{M} \pm \mathrm{SD}\end{array}$} & \multirow{2}{*}{$x^{2}$ or $\mathrm{t}(p)$} \\
\hline & & $\mathrm{n}(\%)$ or $\mathrm{M} \pm \mathrm{SD}$ & & & & \\
\hline \multirow[t]{2}{*}{ Gender } & Male & $192(47.9)$ & & $53(47.3)$ & $139(48.1)$ & \multirow[t]{2}{*}{$0.02(.912)$} \\
\hline & Female & $209(52.1)$ & & $59(52.7)$ & $150(51.9)$ & \\
\hline \multirow[t]{3}{*}{ Grade } & 4th & $129(32.2)$ & & $48(42.8)$ & $81(28.0)$ & \multirow[t]{3}{*}{$9.21(.010)$} \\
\hline & 5 th & $124(30.9)$ & & $33(29.5)$ & 91 (31.5) & \\
\hline & 6th & $148(36.9)$ & & $31(27.7)$ & $117(40.5)$ & \\
\hline $\mathrm{BMI}^{*}$ & & $19.9 \pm 3.9$ & $12.6 \sim 33.3$ & $19.2 \pm 4.0$ & $20.1 \pm 3.9$ & $1.90(.059)$ \\
\hline \multirow[t]{3}{*}{ Adiposity* } & Underweight & $25(7.4)$ & & $10(10.7)$ & $15(6.1)$ & \multirow[t]{3}{*}{$2.20(.334)$} \\
\hline & Normal & $218(64.1)$ & & $58(62.4)$ & $160(64.8)$ & \\
\hline & Overweight or obese & $97(28.5)$ & & $25(26.9)$ & 72 (29.1) & \\
\hline \multirow{3}{*}{$\begin{array}{l}\text { Perceived } \\
\text { health status }\end{array}$} & $\leq$ Unhealthy & $35(8.7)$ & & $9(8.0)$ & $26(9.0)$ & \multirow[t]{3}{*}{$3.93(.140)$} \\
\hline & Healthy & $238(59.4)$ & & $75(67.0)$ & $163(56.4)$ & \\
\hline & Very healthy & $128(31.9)$ & & $28(25.0)$ & $100(34.6)$ & \\
\hline \multirow{3}{*}{$\begin{array}{l}\text { Perceived } \\
\text { economic } \\
\text { status }\end{array}$} & Prosperous & $123(30.7)$ & & $18(16.0)$ & $105(36.3)$ & \multirow[t]{3}{*}{$17.77(<.001)$} \\
\hline & Moderate & $269(67.1)$ & & $89(79.5)$ & $180(62.3)$ & \\
\hline & Poor & $9(2.2)$ & & $5(4.5)$ & $4(1.4)$ & \\
\hline \multirow{5}{*}{$\begin{array}{l}\text { Maternal } \\
\text { nationality }\end{array}$} & Korea & $289(72.1)$ & & $0(0.0)$ & $289(100.0)$ & \multirow[t]{5}{*}{$401.00(<.001)$} \\
\hline & Vietnam & $88(22.0)$ & & $88(78.6)$ & $0(0.0)$ & \\
\hline & Philippines & $9(2.2)$ & & $9(8.0)$ & $0(0.0)$ & \\
\hline & China & $8(2.0)$ & & $8(7.1)$ & $0(0.0)$ & \\
\hline & Other $^{\dagger}$ & $7(1.7)$ & & $7(6.3)$ & $0(0.0)$ & \\
\hline \multirow{5}{*}{$\begin{array}{l}\text { Cohabiting } \\
\text { with family } \\
\text { members }^{\ddagger}\end{array}$} & Father & $348(86.8)$ & & $105(93.8)$ & $243(84.1)$ & $6.58(.009)$ \\
\hline & Mother & $344(85.8)$ & & 81 (72.3) & $263(91.0)$ & $23.10(<.001)$ \\
\hline & Grandparents & $133(33.3)$ & & $67(59.8)$ & $66(22.9)$ & $49.49(<.001)$ \\
\hline & Older siblings & $178(44.0)$ & & $28(25.0)$ & $148(51.4)$ & $22.79(.<001)$ \\
\hline & Younger siblings & $198(49.5)$ & & $63(56.3)$ & $135(46.9)$ & $2.84(.096)$ \\
\hline \multirow{7}{*}{$\begin{array}{l}\text { Health } \\
\text { behaviors }\end{array}$} & Personal hygiene & $30.1 \pm 5.1$ & $10 \sim 40$ & $28.6 \pm 4.8$ & $30.7 \pm 5.2$ & $3.87(<.001)$ \\
\hline & Eating habits & $25.0 \pm 4.3$ & $12 \sim 34$ & $24.4 \pm 4.0$ & $25.3 \pm 4.4$ & $1.91(.057)$ \\
\hline & Exercise & $15.9 \pm 3.6$ & $6 \sim 24$ & $15.3 \pm 3.4$ & $16.1 \pm 3.7$ & $2.00(.046)$ \\
\hline & Mental health & $30.8 \pm 5.0$ & $14 \sim 40$ & $30.0 \pm 4.9$ & $31.1 \pm 5.0$ & $1.99(.047)$ \\
\hline & Disease prevention & $29.7 \pm 5.4$ & $14 \sim 40$ & $28.2 \pm 5.1$ & $30.3 \pm 5.4$ & $3.54(<.001)$ \\
\hline & Injury prevention & $24.0 \pm 4.7$ & $8 \sim 32$ & $23.6 \pm 4.2$ & $24.1 \pm 4.9$ & $0.97(.335)$ \\
\hline & Total & $155.5 \pm 22.3$ & $84 \sim 208$ & $150.0 \pm 19.5$ & $157.6 \pm 23.0$ & $3.32(.001)$ \\
\hline \multirow{6}{*}{$\begin{array}{l}\text { Mother-child } \\
\text { relationship }\end{array}$} & Intimacy/support & $38.5 \pm 9.2$ & $10 \sim 50$ & $35.2 \pm 8.6$ & $39.8 \pm 9.1$ & $4.48(<.001)$ \\
\hline & Authority/control & $27.2 \pm 5.7$ & 7 35 & $25.6 \pm 5.1$ & $27.8 \pm 5.4$ & $3.67(<.001)$ \\
\hline & Parental relationship & $18.0 \pm 5.2$ & $5 \sim 25$ & $16.6 \pm 5.0$ & $18.7 \pm 5.1$ & $3.69(<.001)$ \\
\hline & Great expectations & $15.3 \pm 3.8$ & $4 \sim 20$ & $13.7 \pm 4.0$ & $15.9 \pm 3.6$ & $5.32(<.001)$ \\
\hline & Permissiveness & $14.7 \pm 3.5$ & 4 20 & $14.0 \pm 3.2$ & $15.0 \pm 3.6$ & $2.50(.013)$ \\
\hline & Total & $113.7 \pm 18.8$ & $50 \sim 150$ & $104.5 \pm 15.7$ & $117.1 \pm 18.7$ & $6.75(<.001)$ \\
\hline \multirow[t]{5}{*}{$\begin{array}{l}\text { School } \\
\text { adjustment }\end{array}$} & $\begin{array}{l}\text { Academic attitude/ } \\
\text { rule observance }\end{array}$ & $27.3 \pm 4.8$ & $9 \sim 43$ & $26.4 \pm 4.8$ & $27.7 \pm 4.8$ & $2.22(.027)$ \\
\hline & Relationships with peers & $23.4 \pm 4.0$ & $7 \sim 28$ & $22.8 \pm 4.2$ & $23.7 \pm 4.0$ & $2.03(.043)$ \\
\hline & Relationships with teachers & $25.8 \pm 4.4$ & $8 \sim 32$ & $24.9 \pm 4.9$ & $26.1 \pm 4.2$ & $2.37(.018)$ \\
\hline & School satisfaction & $18.9 \pm 3.9$ & 6 24 & $18.5 \pm 4.1$ & $19.1 \pm 3.9$ & $1.36(.174)$ \\
\hline & Total & $95.4 \pm 14.9$ & $30 \sim 120$ & $92.6 \pm 15.9$ & $96.5 \pm 14.3$ & $2.30(.022)$ \\
\hline Self-efficacy & & $29.2 \pm 5.7$ & $10 \sim 40$ & $28.2 \pm 4.8$ & $29.5 \pm 6.0$ & $2.05(.041)$ \\
\hline
\end{tabular}

${ }^{*} \mathrm{~N}=340$ in total, $\mathrm{n}=93$ in multicultural children, $\mathrm{n}=247$ in non-multicultural children; ${ }^{\dagger}$ Cambodia, Mongolia, Thailand; ${ }^{\dagger}$ Multiple choice item; BMI=Body mass index $\left(\mathrm{kg} / \mathrm{m}^{2}\right)$. 
Table 2. Differences in Health Behaviors by Grade, Economic Status, and Cohabitation with Mother between Multicultural and Nonmulticultural Children

$(N=401)$

\begin{tabular}{|c|c|c|c|c|c|c|c|}
\hline \multirow[t]{2}{*}{ Variables } & \multirow[t]{2}{*}{ Categories } & \multirow[t]{2}{*}{$\mathrm{n}$} & \multicolumn{2}{|c|}{$\begin{array}{l}\text { Multicultural children } \\
\qquad(\mathrm{n}=112)\end{array}$} & \multicolumn{2}{|c|}{$\begin{array}{l}\text { Non-multicultural children } \\
\qquad(\mathrm{n}=289)\end{array}$} & \multirow[t]{2}{*}{$\mathrm{t}(p)$} \\
\hline & & & $\mathrm{M} \pm \mathrm{SD}$ & t or $\mathrm{F}(p)$ & $\mathrm{M} \pm \mathrm{SD}$ & $\mathrm{t}$ or $\mathrm{F}(p)$ & \\
\hline \multirow[t]{3}{*}{ Grade } & 4th & 129 & $151.0 \pm 18.9$ & \multirow{3}{*}{$0.15(.864)$} & $156.6 \pm 24.6$ & \multirow[t]{3}{*}{$0.14(.874)$} & $1.45(.149)$ \\
\hline & 5 th & 124 & $148.6 \pm 21.3$ & & $157.5 \pm 24.8$ & & $1.83(.070)$ \\
\hline & 6th & 148 & $149.9 \pm 19.1$ & & $158.3 \pm 20.5$ & & $2.07(.040)$ \\
\hline \multirow{3}{*}{$\begin{array}{l}\text { Perceived } \\
\text { economic status }\end{array}$} & Prosperous $^{\mathrm{a}}$ & 123 & $149.8 \pm 21.3$ & \multirow[t]{3}{*}{$0.12(.888)$} & $162.7 \pm 22.6$ & \multirow{3}{*}{$\begin{array}{c}5.73(.004) \\
b<c^{*}\end{array}$} & $2.26(.026)$ \\
\hline & Moderate $^{\mathrm{b}}$ & 269 & $149.8 \pm 19.1$ & & $154.2 \pm 22.8$ & & $1.69(.093)$ \\
\hline & Poor $^{c}$ & 9 & $154.2 \pm 25.3$ & & $174.0 \pm 13.4$ & & $1.40(.204)$ \\
\hline \multirow{2}{*}{$\begin{array}{l}\text { Cohabiting with } \\
\text { mother }\end{array}$} & Yes & 344 & $152.2 \pm 19.7$ & \multirow[t]{2}{*}{$1.95(.054)$} & $158.7 \pm 22.2$ & \multirow[t]{2}{*}{$2.24(.033)$} & $2.37(.018)$ \\
\hline & No & 57 & $144.2 \pm 18.1$ & & $146.2 \pm 27.6$ & & $0.31(.757)$ \\
\hline
\end{tabular}

*Post hoc analysis=Scheffé test, $p<.050$.

Table 3. Comparison of Health Behaviors According to Characteristics among Multicultural Children

$(N=112)$

\begin{tabular}{|c|c|c|c|c|c|c|c|c|c|}
\hline \multirow[t]{2}{*}{ Variables } & \multirow[t]{2}{*}{ Categories } & \multirow[t]{2}{*}{$\mathrm{n}$} & $\begin{array}{c}\text { Total } \\
\text { health } \\
\text { behavior }\end{array}$ & $\begin{array}{l}\text { Personal } \\
\text { hygiene }\end{array}$ & $\begin{array}{l}\text { Eating } \\
\text { habits }\end{array}$ & Exercise & $\begin{array}{l}\text { Mental } \\
\text { health }\end{array}$ & $\begin{array}{c}\text { Disease } \\
\text { prevention }\end{array}$ & $\begin{array}{c}\text { Injury } \\
\text { prevention }\end{array}$ \\
\hline & & & $\mathrm{M} \pm \mathrm{SD}$ & $\mathrm{M} \pm \mathrm{SD}$ & $\mathrm{M} \pm \mathrm{SD}$ & $\mathrm{M} \pm \mathrm{SD}$ & $\mathrm{M} \pm \mathrm{SD}$ & $\mathrm{M} \pm \mathrm{SD}$ & $\mathrm{M} \pm \mathrm{SD}$ \\
\hline Gender & $\begin{array}{l}\text { Male } \\
\text { Female } \\
\mathrm{t}(p)\end{array}$ & $\begin{array}{l}53 \\
59\end{array}$ & $\begin{array}{c}146.6 \pm 21.0 \\
153.0 \pm 17.8 \\
1.72(.087)\end{array}$ & $\begin{array}{c}28.3 \pm 4.5 \\
28.8 \pm 5.0 \\
0.52(.604)\end{array}$ & $\begin{array}{c}23.8 \pm 4.3 \\
24.9 \pm 3.7 \\
1.36(.176)\end{array}$ & $\begin{array}{c}14.9 \pm 3.3 \\
15.6 \pm 3.5 \\
1.09(.277)\end{array}$ & $\begin{array}{c}29.4 \pm 5.2 \\
30.5 \pm 4.7 \\
1.22(.226)\end{array}$ & $\begin{array}{c}27.4 \pm 5.6 \\
28.9 \pm 4.6 \\
1.53(.129)\end{array}$ & $\begin{array}{c}22.8 \pm 4.5 \\
24.3 \pm 3.7 \\
1.95(.054)\end{array}$ \\
\hline Grade & $\begin{array}{l}4 \text { th } \\
5 \text { th } \\
6 \text { th } \\
\mathrm{F}(p)\end{array}$ & $\begin{array}{l}48 \\
33 \\
31\end{array}$ & $\begin{array}{c}151.0 \pm 18.9 \\
148.6 \pm 21.3 \\
149.9 \pm 19.1 \\
0.15(.864)\end{array}$ & $\begin{array}{c}27.5 \pm 4.8 \\
29.6 \pm 4.1 \\
29.2 \pm 5.1 \\
2.32(.103)\end{array}$ & $\begin{array}{c}25.2 \pm 3.6 \\
23.1 \pm 4.0 \\
24.4 \pm 4.4 \\
2.77(.067)\end{array}$ & $\begin{array}{c}15.2 \pm 3.4 \\
15.1 \pm 3.4 \\
15.7 \pm 3.5 \\
0.23(.796)\end{array}$ & $\begin{array}{c}30.5 \pm 5.1 \\
29.6 \pm 4.9 \\
29.5 \pm 4.7 \\
0.48(.619)\end{array}$ & $\begin{array}{c}28.3 \pm 5.1 \\
28.4 \pm 5.4 \\
27.7 \pm 4.9 \\
0.16(.852)\end{array}$ & $\begin{array}{c}24.3 \pm 3.4 \\
22.8 \pm 5.0 \\
23.4 \pm 4.2 \\
1.42(.245)\end{array}$ \\
\hline Adiposity* & $\begin{array}{l}\text { Underweight }^{\mathrm{a}} \\
\text { Normal }^{\mathrm{b}} \\
\text { Overweight or }^{\mathrm{c}} \\
\text { obese }^{\mathrm{c}} \\
\mathrm{F}(p)\end{array}$ & $\begin{array}{l}10 \\
58 \\
25\end{array}$ & $\begin{array}{l}138.4 \pm 17.4 \\
149.8 \pm 19.9 \\
155.8 \pm 16.7 \\
3.11(.050)\end{array}$ & $\begin{array}{r}27.8 \pm 5.1 \\
28.8 \pm 4.7 \\
30.0 \pm 4.1 \\
1.04(.357)\end{array}$ & $\begin{array}{r}22.7 \pm 4.2 \\
24.2 \pm 4.2 \\
25.2 \pm 3.7 \\
1.37(.261)\end{array}$ & $\begin{array}{l}13.1 \pm 4.5 \\
15.8 \pm 3.0 \\
15.0 \pm 3.7 \\
2.80(.066)\end{array}$ & $\begin{array}{r}28.8 \pm 4.7 \\
29.6 \pm 5.3 \\
31.2 \pm 3.4 \\
1.39(.254)\end{array}$ & $\begin{array}{c}23.9 \pm 3.5 \\
28.1 \pm 4.8 \\
30.2 \pm 4.6 \\
6.54(.002) \\
a<b, c^{\dagger}\end{array}$ & $\begin{array}{l}22.1 \pm 4.9 \\
23.3 \pm 4.2 \\
24.2 \pm 4.1 \\
0.93(.398)\end{array}$ \\
\hline $\begin{array}{l}\text { Perceived } \\
\text { health status }\end{array}$ & $\begin{array}{l}\leq \text { Unhealthy }^{\mathrm{a}} \\
\text { Healthy }^{\mathrm{b}} \\
\text { Very healthy } \\
\mathrm{F}(p)\end{array}$ & $\begin{array}{r}9 \\
75 \\
28\end{array}$ & $\begin{array}{c}142.4 \pm 22.5 \\
146.2 \pm 17.6 \\
162.4 \pm 18.7 \\
8.81(<.001) \\
\text { a, b }<c^{\dagger}\end{array}$ & $\begin{array}{c}27.5 \pm 5.0 \\
27.9 \pm 4.7 \\
30.6 \pm 4.5 \\
3.54(.033) \\
b<c^{\dagger}\end{array}$ & $\begin{array}{c}23.8 \pm 4.1 \\
23.7 \pm 3.8 \\
26.4 \pm 3.9 \\
5.23(.007) \\
b<c^{\dagger}\end{array}$ & $\begin{array}{c}13.1 \pm 3.8 \\
15.2 \pm 3.3 \\
16.3 \pm 3.4 \\
3.31(.040) \\
\mathrm{a}<\mathrm{c}^{\dagger}\end{array}$ & $\begin{array}{c}29.1 \pm 4.6 \\
29.2 \pm 4.4 \\
32.3 \pm 5.7 \\
4.37(.015) \\
\mathrm{b}<\mathrm{c}^{\dagger}\end{array}$ & $\begin{array}{c}26.8 \pm 4.9 \\
27.0 \pm 4.8 \\
31.6 \pm 4.5 \\
9.95(<.001) \\
\mathrm{a}, \mathrm{b}<\mathrm{c}^{\dagger}\end{array}$ & $\begin{array}{c}22.1 \pm 5.3 \\
23.2 \pm 4.0 \\
25.2 \pm 4.0 \\
3.05(.051)\end{array}$ \\
\hline $\begin{array}{l}\text { Perceived } \\
\text { economic } \\
\text { status }\end{array}$ & $\begin{array}{l}\text { Prosperous } \\
\text { Moderate } \\
\text { Poor } \\
\mathrm{F}(p)\end{array}$ & $\begin{array}{r}18 \\
89 \\
5\end{array}$ & $\begin{array}{c}149.8 \pm 21.3 \\
149.8 \pm 19.1 \\
154.2 \pm 25.3 \\
0.12(.888)\end{array}$ & $\begin{array}{c}28.8 \pm 4.5 \\
28.3 \pm 4.8 \\
31.8 \pm 4.5 \\
1.26(.287)\end{array}$ & $\begin{array}{c}23.3 \pm 3.7 \\
24.5 \pm 4.1 \\
25.6 \pm 4.1 \\
0.89(.414)\end{array}$ & $\begin{array}{c}15.2 \pm 3.2 \\
15.3 \pm 3.5 \\
15.8 \pm 3.9 \\
0.06(.943)\end{array}$ & $\begin{array}{c}30.7 \pm 4.9 \\
30.0 \pm 4.7 \\
26.6 \pm 7.7 \\
1.37(.260)\end{array}$ & $\begin{array}{c}28.2 \pm 6.0 \\
28.1 \pm 4.9 \\
29.4 \pm 5.9 \\
0.16(.855)\end{array}$ & $\begin{array}{c}23.6 \pm 4.3 \\
23.5 \pm 4.1 \\
25.0 \pm 4.8 \\
0.29(.746)\end{array}$ \\
\hline $\begin{array}{l}\text { Cohabiting } \\
\text { with mother }\end{array}$ & $\begin{array}{l}\text { Yes } \\
\text { No } \\
\mathrm{t}(p)\end{array}$ & $\begin{array}{l}81 \\
31\end{array}$ & $\begin{array}{c}152.2 \pm 19.7 \\
144.2 \pm 18.1 \\
1.95(.054)\end{array}$ & $\begin{array}{c}29.0 \pm 4.9 \\
27.4 \pm 4.4 \\
1.59(.115)\end{array}$ & $\begin{array}{c}24.7 \pm 4.1 \\
23.5 \pm 3.8 \\
1.46(.148)\end{array}$ & $\begin{array}{c}15.5 \pm 3.4 \\
14.7 \pm 3.4 \\
1.19(.236)\end{array}$ & $\begin{array}{c}30.5 \pm 4.6 \\
28.6 \pm 5.5 \\
1.83(.070)\end{array}$ & $\begin{array}{c}28.5 \pm 5.4 \\
27.2 \pm 4.2 \\
1.23(.220)\end{array}$ & $\begin{array}{c}23.9 \pm 4.1 \\
22.8 \pm 4.2 \\
1.21(.228)\end{array}$ \\
\hline $\begin{array}{l}\text { Cohabiting } \\
\text { with } \\
\text { grandparent }\end{array}$ & $\begin{array}{l}\text { Yes } \\
\text { No } \\
\mathrm{t}(p)\end{array}$ & $\begin{array}{l}67 \\
45\end{array}$ & $\begin{array}{c}151.1 \pm 17.9 \\
148.2 \pm 21.9 \\
0.77(.442)\end{array}$ & $\begin{array}{c}28.1 \pm 5.2 \\
29.2 \pm 4.1 \\
1.16(.248)\end{array}$ & $\begin{array}{c}24.9 \pm 3.6 \\
23.6 \pm 4.5 \\
1.78(.077)\end{array}$ & $\begin{array}{c}15.1 \pm 3.4 \\
15.5 \pm 3.5 \\
0.61(.545)\end{array}$ & $\begin{array}{c}30.5 \pm 4.9 \\
29.2 \pm 4.9 \\
1.45(.151)\end{array}$ & $\begin{array}{c}28.4 \pm 5.0 \\
27.8 \pm 5.2 \\
0.67(.503)\end{array}$ & $\begin{array}{c}24.0 \pm 3.4 \\
23.0 \pm 5.0 \\
1.14(.259)\end{array}$ \\
\hline $\begin{array}{l}\text { Older sister or } \\
\text { brother }\end{array}$ & $\begin{array}{l}\text { Have } \\
\text { None } \\
\mathrm{t}(p)\end{array}$ & $\begin{array}{l}28 \\
84\end{array}$ & $\begin{array}{c}152.1 \pm 19.8 \\
148.7 \pm 18.8 \\
0.81(.422)\end{array}$ & $\begin{array}{c}29.5 \pm 4.8 \\
28.2 \pm 4.7 \\
1.28(.205)\end{array}$ & $\begin{array}{c}23.8 \pm 4.1 \\
24.5 \pm 3.9 \\
0.74(.463)\end{array}$ & $\begin{array}{c}15.6 \pm 3.4 \\
15.1 \pm 3.3 \\
0.72(.471)\end{array}$ & $\begin{array}{c}31.7 \pm 4.5 \\
29.3 \pm 4.8 \\
2.31(.023)\end{array}$ & $\begin{array}{c}28.6 \pm 5.3 \\
27.9 \pm 4.9 \\
0.61(.544)\end{array}$ & $\begin{array}{c}22.8 \pm 4.0 \\
23.8 \pm 4.1 \\
1.05(.298)\end{array}$ \\
\hline
\end{tabular}

${ }^{*} \mathrm{n}=93 ;{ }^{\dagger}$ Post hoc analysis=Scheffé test, $p<.050$. 
Table 4. Correlation among Health Behaviors and Main Variables among Multicultural Children

$(N=112)$

\begin{tabular}{|c|c|c|c|c|c|c|c|}
\hline Variables & $\begin{array}{c}\text { Total } \\
\text { health } \\
\text { behavior }\end{array}$ & $\begin{array}{l}\text { Personal } \\
\text { hygiene }\end{array}$ & $\begin{array}{c}\text { Eating } \\
\text { habit }\end{array}$ & Exercise & $\begin{array}{l}\text { Mental } \\
\text { health }\end{array}$ & $\begin{array}{c}\text { Disease } \\
\text { prevention }\end{array}$ & $\begin{array}{c}\text { Injury } \\
\text { prevention }\end{array}$ \\
\hline & $r(p)$ & $\mathrm{r}(p)$ & $\mathrm{r}(p)$ & $\mathrm{r}(p)$ & $\mathrm{r}(p)$ & $\mathrm{r}(p)$ & $\mathrm{r}(p)$ \\
\hline Mother-child relationship & $.37(<.001)$ & $.32(.001)$ & $.24(.015)$ & $.22(.021)$ & $.39(<.001)$ & $.28(.004)$ & $.19(.053)$ \\
\hline School adjustment & $.62(<.001)$ & $.38(<.001)$ & $.30(.002)$ & $.24(.015)$ & $.74(<.001)$ & $.44(<.001)$ & $.56(<.001)$ \\
\hline Self-efficacy & $.44(<.001)$ & $.24(.014)$ & $.18(.063)$ & $.23(.017)$ & $.52(<.001)$ & $.39(<.001)$ & $.40(<.001)$ \\
\hline Body mass index* & $.19(.067)$ & $.21(.041)$ & $.19(.073)$ & $.02(.860)$ & $.05(.609)$ & $.26(.013)$ & $.08(.471)$ \\
\hline
\end{tabular}

Table 5. Factors Affecting Health Behaviors in Multicultural Children

$(N=102)$

\begin{tabular}{|c|c|c|c|c|c|}
\hline Variables & B & SE & $\beta$ & $\mathrm{t}$ & $p$ \\
\hline (Constant) & 53.17 & 12.91 & & 7.09 & $<.001$ \\
\hline Perceived health status (Ref.: $\leq$ healthy) & 8.03 & 3.11 & .19 & 2.58 & .011 \\
\hline Mother-child relationship & 0.32 & 0.09 & .25 & 3.40 & .001 \\
\hline \multirow[t]{2}{*}{ School adjustment } & 0.74 & 0.10 & .55 & 7.35 & $<.001$ \\
\hline & \multicolumn{5}{|c|}{ Adj. $\mathrm{R}^{2}=.47, \mathrm{~F}=30.93, p<.001$} \\
\hline
\end{tabular}

Ref.=Reference.

children's behavior from the surrounding environment becomes stronger than previously. Since multicultural children are likely to be in a vulnerable condition regarding health behavior practices, this study investigated the health behaviors of multicultural late school-aged children and the factors affecting those behaviors by analyzing self-reported data from fourth- to sixth-grade elementary students in rural areas with a high proportion of multicultural students, and obtained the following meaningful results.

First of all, multicultural children are at risk of having poor health behavior practices. In this study, the overall score for multicultural children's health behaviors and the scores for all the subcategories showed a tendency to be lower than the corresponding scores of non-multicultural children. Due to their vulnerable family characteristics, multicultural children have a high risk of not being able to receive proper health care starting early in their lives, which may also exert a negative influence on children's independent health behaviors subsequently [3]. However, few domestic studies have investigated the health behaviors of multicultural children, especially those of late school-age children, and our study is therefore significant in being a groundbreaking study demonstrating that multicultural children constitute a health behavior-disadvantaged group. Meanwhile, in Park's study [9], which used the same health behavior measurement tools as our study to investigate 297 fourth- through sixth-grade elementary students from low-income families in Seoul, the total average score was $167.4 \pm 22.5$, while our study obtained average scores of 150.0 \pm 19.5 points for multicultural children and $155.5 \pm 22.3$ points for all subjects, including non-multicultural children, reflecting a major difference from the findings of Park [9] (by more than 10 points). Since the subjects of Park's study [9] were children from low-income families who were cared for at local children's centers in big cities, it is reasonable to infer that the difference in health behavior scores between the subjects of these two studies is related to differences between residential districts (large cities vs. rural villages and towns). It is possible for rural areas to have a more vulnerable physical environment related to health behaviors, given a relative lack of public sports facilities, parks, and access to healthcare than urban areas; furthermore, the sparse availability of health teachers due to the small number of students and limited administrative manpower [1] might have had negative influences on perceptions and practices of health behaviors by undermining school health education programs. Moreover, a study that compared marriage migrant women in urban and rural areas [24] reported that compared to city-dwelling women, those in rural areas had lower socioeconomic status and poorer levels of adaptation to Korea, as reflected by their education levels, monthly income, and Korean-language proficiency, as well as the low education levels of their spouses. In other words, multicultural children in rural communities are vulnerable due to 
family-related factors on top of regional disadvantages, putting them at a double disadvantage in relation to health behaviors. Therefore, further research should investigate the health behavior gap between regions, as well as reinforcing health behavior-promoting educational interventions for multicultural children.

Multicultural children presented significantly lower scores for the mother-child relationship and school adjustment than non-multicultural students, in addition to their poorer scores for health behaviors, suggesting that multicultural children's environmental support system may also be vulnerable. This study supports the results of previous studies $[15,25]$ that reported poor-quality mother-child relationships in multicultural families, due to the fact that mothers of multicultural families immigrate at the time of marriage and, in a short time frame, experience the drastic change of childbirth in addition to facing the burden of child-rearing, a combination that contributes to high parenting stress and low maternal identity, placing them at a greater risk of difficulties in mother-child bonding from the early stages of their children's lives [25]. Subsequently, it becomes easier to use physical instead of verbal punishment as the child grows and the mother's Koreanlanguage proficiency falls short compared to that of her child, and school enrollment may cause mother-child conflicts due to the child's disrespect toward the mother, who is unfamiliar with educational programs and culture in Korea [15]. Therefore, to improve mother-child relationships in multicultural families, an approach needs to be taken starting early in children's lives that utilizes practical strategies, such as the ongoing operation of individual consultation programs, to resolve mother-child conflicts and to promote attachment. Multicultural children are unlikely to receive proper support even at school, and a qualitative study [26] on the experiences of elementary school teachers in guiding multicultural children found that multicultural children had poor learning outcomes due to their weak Korean writing ability, learning readiness, and comprehension, and that teachers faced difficulties in dealing with these children's frequent behavioral problems such as stealing, distractions, violence, and violations of school regulations. Furthermore, parents' ability to provide guidance to multicultural children was hindered by the mothers' communication problems, passive attitudes towards educating their children, and poor understanding of their children and school culture [26], and there were limits to the degree to which teachers' individual efforts alone could improve the school adjustment of multicultural children. We suggest that a more multidimensional approach incorporating a deeper connection between the school and the local community for the children and their families would be more effective for promoting school adjustment in multicultural children.
A second major finding of this study is the health behaviors of multicultural children showed correlations with some of their internal characteristics, such as grade and adiposity. In a study that targeted fifth- and sixth-graders in elementary school [6,7], the health behavior score of fifth-graders was significantly higher than that of sixth-graders, suggesting that children in lower grades might have higher levels of health behavior practices. There was no significant difference in health behavior scores according to grade in this study, but the difference in health behavior scores between multicultural and non-multicultural children became more distinctive as the students advanced through school, with multicultural children in sixth grade showing a lower average score than the non-multicultural children by about 8.4 points, which was statistically significant. For this reason, health behavior education for multicultural children should be reinforced starting in the lower grades and repeated throughout the higher grades to help these children to consistently practice and improve health behaviors. Additionally, the health behavior score of underweight children tended to be lower than that of normal or overweight/obese children in our study, in contrast to the findings of Oh's study [6] in which underweight children had higher health behavior scores than overweight children. Being overweight or obese, which is likely the outcome of inappropriate eating habits and physical activity, should not be overlooked considering the various negative influence of obesity on relationships with peers at school, long-term social adjustment, and health problems. However, since underweight children are over-represented at low socioeconomic levels, and are susceptible to deficient care [27] as much as obese children, healthcare policy should not overlook the problems faced by underweight children, considering the negative influence of nutritional deficiencies on children's learning ability, growth, and development.

As a third important finding, we discovered that the predictors of multicultural children's health behaviors were perceived health status, the mother-child relationship, and school adjustment. Many recent studies in Korea on late school-age non-multicultural children [6-9] have consistently reported that the more positively children assess their health status, the higher their health behavior scores. Perceived health status was likewise demonstrated to be a predictor of multicultural children's health behaviors $(\beta=.19, p=.011)$ in our study, proving that subjective health status is a quite reliable indicator for predicting health behaviors in children, including multicultural students, and can be used as an easy, simple tool in various child care environments, ranging from clinics to schools and local communities. In addition, the low perceived health status and self-efficacy of multicultural children can be considered as reflective of their tendency to give poor sub- 
jective evaluations of themselves. Since school-age children show a strong dependence on aspects of their surroundings such as peers, teachers, and families, rather than autonomous standards, for self-evaluation [5], it is essential that support for multicultural children in families and schools be reinforced even more.

Mothers still exert a major influence on school-aged children, and we verified that the mother-child relationship independently affected the health behaviors of multicultural children $(\beta=.25, p=.001)$. This result is in agreement with those of previous studies, in which the relationship of parents and vulnerable children between 6 and 12 years of age was found to be correlated to dietary patterns such as the intake of fast foods, sweetened drinks, and fruits and vegetables [10]. The findings of this study are also consistent with those of another study in which parental attachment in fourth- to sixthgrade elementary students, as evaluated by emotional intimacy toward their parents, showed a positive correlation with health behaviors, emerging as a factor affecting health behaviors in multiple regression analysis [6]. The proportion of multicultural children who cohabited with their mothers was significantly lower than that of non-multicultural children, which can be inferred to have resulted from divorce or separation of the parents, as there is a high risk of family dissolution resulting from conflicts between parents and family members in multicultural households [2]. Nonetheless, cohabitation with the mother did not show a significant correlation with children's health behaviors, indicating that the quality of the relationship, rather than physical cohabitation with the mother, is what strongly affects children's behavior.

School adjustment, reflecting the fact that school is an intimate environment for school-aged children (along with the familial setting), was the strongest predictor of multicultural children's health behaviors $(\beta=.55, p<.001)$. This is consistent with the result of a study on late school-aged non-multicultural children, in which those with higher satisfaction with their school life had higher health behavior scores than children with lower-than-average satisfaction [7]. Our study, which included not only school satisfaction, but also attitudes towards academic achievements, observance of regulations, and relationships with peers and teachers in the evaluation of school adjustment, demonstrated that school life as a whole has important implications for multicultural children's health behaviors. In a previous study of third- to sixth-grade elementary students [28], the entire range of school adjustment criteria-including relationships with teachers and peers, learning activities, school regulations, and school event participation-was related to cell phone overuse, supporting the fact that school adjustment is an important factor that influences health behaviors. In particular, school adjustment showed the strongest correlation with mental health behavior $(\mathrm{r}=.74, p<$ .001) among the subcategories of health behaviors. This is similar to the results of a study of fourth- to sixth-grade elementary students [17], which showed that multicultural children were more frequently bullied within their relationships with school friends than non-multicultural children, and that bullying led to negative mental states such as intimidation, anxiety, and depression, underscoring the need to pay attention to multicultural children's school adjustment, especially successful adaptation to school life in terms of peer relationships.

Furthermore, this study showed a significant correlation between the self-efficacy of multicultural children and their health behaviors in the univariate analysis, in parallel with Jeon's study [7], which confirmed that perceived behavior control, a parameter conceptually similar to self-efficacy, affected late school-aged children's health behaviors $(\beta=.38$, $p<.001)$. However, unlike Jeon's results [7], self-efficacy was not identified as an independent factor affecting health behaviors in this study through multiple regression analysis. Considering that self-efficacy is a strong factor that stimulates certain behaviors and is deeply related to health behavior performance [15], the relationship between self-efficacy and health behaviors might have been undervalued, as this study evaluated self-efficacy in terms of convictions about one's capability to engage in ordinary behaviors, rather than direct health behaviors. It is suggested that further studies explore the relationship between health behaviors among multicultural children and more direct measures of self-efficacy in relation to health behaviors.

\section{CONCLUSION}

This study investigated the levels of health behaviors among multicultural children in comparison with non-multicultural children and analyzed the factors affecting multicultural children's health behaviors. Multicultural children were identified as a disadvantaged group in terms of health behaviors since their level of health behaviors was lower than that of non-multicultural children, and the predictors of their health behaviors were subjective health status perceived by children, the mother-child relationship, and school adjustment. Subjective health status was reconfirmed through this study as a very useful tool for predicting children's health behaviors. Since mother-child relationships and school adjustment as perceived by the children were lower for multicultural children than for non-multicultural children, nursing intervention strategies to promote these factors as a way of improving health behaviors among multicultural children are warranted.

Most of the mothers of the subjects of this study were of Vietnamese nationality $(78.6 \%)$, followed by Filipina $(8.0 \%)$ 
and Chinese $(7.1 \%)$. This reflects the fact that students with Vietnamese mothers tend to be dispersed more intensely throughout towns and villages (i.e., in rural areas). Considering that cities have greater proportions of students with Chinese or Korean-Chinese mothers relative to students with Vietnamese mothers [1], it is unreasonable to generalize the results of this study, which was based on town and village areas in a single province, to the entire group of multicultural elementary students. Furthermore, the cross-sectional design of this study means that there are limitations in determining the cause-and-effect relationships between variables. Nevertheless, this is a novel study that extensively explored the health behaviors of school-aged multicultural children and identified predictors of health behaviors, and it is significant in that it provides the basic information needed to establish a health behavior promotion strategy for multicultural children.

\section{Conflict of interest}

No existing or potential conflict of interest relevant to this article was reported.

\section{REFERENCES}

1. Ministry of Education; Korean Educational Development Institute. 2018 Statistical yearbook of education [Internet]. Chungcheongbuk-do: Korean Educational Development Institute; 2018 [cited 2019 August 27]. Available from:

https:// kess.kedi.re.kr/publ/view?survSeq=2018\&menuSeq=3894 \&publSeq $=2 \&$ itemCode $=02 \&$ menuId $=0$ \&language $=$ en $\#$

2. Korean Women's Development Institute. The national survey of multicultural familes 2018. Study Report. Sejong: National Ministry of Gender Equality and Family; 2019 March. Report No.: 2019-01.

3. Kim HR. Health problems and policy implications in multicultural families. Health ·Welfare Issue and Focus. 2013;12:1-8.

4. Lally P, Gardner B. Promoting habit formation. Health Psychology Review. 2013;7(sup1): S137-S158.

https://doi.org/10.1080/17437199.2011.603640

5. Hockenberry M, Wilson D. Wong's nursing care of infant and children. 10th ed. St. Louis: Mosby; 2014. p. 569-583.

6. Oh JA. Factors affecting the health behavior of elementary school children at a late school age. Journal of Korean Academy of Community Health Nursing. 2010:21(4);458-467.

7. Jeon GE, Kwon IS. Factors affecting health promotion behaviors of upper grade elementary students. Child Health Nursing Research. 2017;23(3):319-328. https://doi.org/10.4094/chnr.2017.23.3.319

8. Jang BS, Kim DH. Health literacy and health behavior in late school-age children. Journal of Korean Academy of Community Health Nursing. 2015;26(3):199-208.

https://doi.org/10.12799/jkachn.2015.26.3.199
9. Park J. Predictors of health promoting behaviors among children from low-income families: An ecological approach [dissertation]. Seoul: Yonsei University; 2014. p. 1-181.

10. Kim S, Choo J. Health Behaviors and health-related quality of life among vulnerable children in a community. Journal of Korean Academy of Community Health Nursing. 2015;26(3):292-302. https://doi.org/10.12799/jkachn.2015.26.3.292

11. Kim EG, Yoo H. Health behaviors and health status by gender differences of adolescents in multicultural families. Journal of the Korean Society of School Health. 2018;31(1):10-17.

https://doi.org/10.15434/kssh.2018.31.1.10

12. Short SE, Mollborn S. Social determinants and health behaviors: Conceptual frames and empirical advances. Current Opinion in Psychology. 2015;5:78-84.

https://doi.org/10.1016/j.copsyc.2015.05.002

13. Schwarzer R, Luszczynska A. Perceived self-efficacy [Internet]. Washington, D.C: National Cancer Institute; 2008 [cited 2019 August 27]. Available from:

https://cancercontrol.cancer.gov/brp/research/constructs/self_ efficacy.html

14. Yee AZ, Lwin MO, Ho SS. The influence of parental practices on child promotive and preventive food consumption behaviors: A systematic review and meta-analysis. International Journal of Behavioral Nutrition and Physical Activity. 2017;14(1):47. https://doi.org/10.1186/s12966-017-0501-3

15. Song SH, An HJ. Experience of child-rearing of filipino married immigrant women. Journal of Korean Academy of Psychiatric and Mental Health Nursing. 2011;20(2):167-179. https://doi.org/10.12934/jkpmhn.2011.20.2.167

16. Joe SJ, Doh HS. The development and validation of a school adjustment scale for late school-aged children. Korean Journal of Child Studies. 2018;39(2):95-111.

https://doi.org/10.5723/kjcs.2018.39.2.95

17. Oh I. Relations between school bullying victimization and psychological problems among students from multicultural families: A focus on mediation effect of psychological well-being. Asian Journal of Education. 2014;15(4):219-238.

18. Shin KM, Cho SM, Shin YM, Park KS. Effects of early childhood peer relationships on adolescent mental health: A 6- to 8-year follow-up study in South Korea. Psychiatry Investigation. 2016;13(4): 383-388. https://doi.org/10.4306/pi.2016.13.4.383

19. Kim SJ, Yang SO, Jeong GH, Lee SH. Level of health promotion behavior practice in elementary school students. Journal of Korean Academy of Child Health Nursing. 2007;13(4):407-415.

20. Kim JH, Yun S, Hwang S, Shim JO, Chae HW, Lee YJ, et al. The 2017 Korean national growth charts for children and adolescents: Development, improvement, and prospects. Korean Journal of Pediatrics. 2018;61(5):135-149. https://doi.org/10.3345/kjp.2018.61.5.135

21. Lee MK, Kim SH. Development of a parent-child relationships 
scale for upper grade elementary school students. Korea Journal of Counseling. 2011;12(3):997-1017.

22. Lee YM, Schwarzer R, Jerusalem M. Korean adaptation of the general self-efficacy scale [Internet]. United Kingdom: NFER-Nelson; 1994 [Cited 2019 April 20]. Available from:

http://userpage.fu-berlin.de/ health/korean.htm

23. Schwarzer R, Jerusalem M. The general self-efficacy scale [Internet]. United Kingdom: NFER-Nelson; 1993 [Cited 2019 April 20]. Available from:

http://userpage.fu-berlin.de/ health/engscal.htm

24. Nam IS, Ahn S. Comparison of stress, social support, and marital satisfaction between married immigrant women in urban and rural areas. Korean Journal of Women Health Nursing. 2011;17(2): 99-108. https://doi.org/10.4069/kjwhn.2011.17.2.99

25. Song JE, Roh EH, Park SM. Systematic review of quantitative re- search related to maternal adaptation among women immigrants by marriage in Korea. Korean Journal of Women Health Nursing. 2015;21(1):55-70. https://doi.org/10.4069/kjwhn.2015.21.1.55

26. Hwang HH. Current status and implication of multicultural students. Issues Report. Seoul: National Assembly Research Service; 2018 November. Report No.: 131-20181114.

27. Pearce A, Rougeaux E, Law C. Disadvantaged children at greater relative risk of thinness (as well as obesity): A secondary data analysis of the England national child measurement programme and the UK millennium cohort study. International Journal for Equity in Health. 2015;14:61. https://doi.org/10.1186/s12939-015-0187-6

28. Lee KS, Ahn HR, Lee KH. Factors related to the overuse of mobile phone in elementary school students. Journal of Korean Academy of Psychiatric Mental Health Nursing. 2011;20(3):271-280. 